\title{
時変系に対する適応制御
}

\author{
———統一的アプローチ— \\ 新中新二*・鈴木 隆**
}

\section{A New Method to Design Adaptive Controllers for Time-Varying Plants}

-A Unified Approach-

Shinji ShInNaka* and Takashi Suzuki**

\begin{abstract}
Although a number of methods have been reported to design adaptive controllers for the plants described as linear time-invariant systems, a few as linear time-varying systems. However, these recent methods for time-varying plants require crucial design conditions on parameter varition of plants, dead-time, inverse stability, and their application to existing plants is restricted. This paper presents a new method to design adaptive controllers for linear time-varying plants, which does not require such conditions at all. It is such a general method as can be applied to the plants which others cannot and includes most of principal conventional ones as special cases.
\end{abstract}

Key Words : adaptive control, self-tuning control, time-varying plant

\section{1. まえがき}

時変プラントに対する適応制御法としては，従来よ り，基礎設計においてはプラントを時不変系として扱 い，パラメータ調整に際して忘却係数を有する適応形 のアルゴリズムを導入し，プラントの特性変動をコン トローラパラメータに反映させるという方法が広く用 いられ, 特性変動が比較的緩やかな場合にはその有用 性は評価されてきた

このような方法に代わって，当初よりプラントを時

†第 28 回自動制御連合講演会で発表（昭 $60 \cdot 11$ ) 第 6 回適応制御シンポジウムで発表（昭 $61 \cdot 1$ )

* キャノン(株)事務機システムセンター 東京都大田区 下丸子 3-30-2

** 防衛大学校 横須賀市走水 1-10-20

* Office Systems Center, Canon Inc., Ohta-ku, Tokyo

** The National Defense Academy, Yokosuka (Received February 4, 1986)

(Revised August 7, 1986)
変系として記述して制御系を設計しようとする積極的 な方法が最近 $2 ， 3$ 報告されている2 ${ }^{2)-5)}$ ててれらの方 法は，所要の条件が正しく満足されれば，従来のもの をしのぐ制御系の設計を可能にするあのではあるが， その条件は, プラントパラメータは，ある特定のレー トで漸近的に一定值に収束する ${ }^{2), 3)}$ ，あるいは特定の 周期で正弦波状に変動する4)など，かなり制約的なむ のになっている.プラントのむだ時間に関してはてれ は 1 サンプリング周期でなくてはならず2),4),5)(文献 3) では，パラメータが，ある特定のレートで一定值に取 束するプラントに対して，1 サンプリング周期以上の むだ時間を有する場合にも使用しうる一設計法が示さ れている), しかも, パラメータ調整のためのアルゴ リズムは適応性の低い忘却係数のないあのに限定され ており（たとえば，ゲイン行列を終始一定に保つ固定

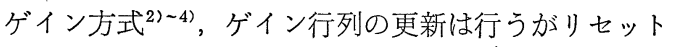
の繰返しが必要なリセットゲイン方式 ${ }^{5)}$ ), 所要の条件 が正確に満足されない場合には, 従来の方法を必ずし あしのぎうるあのではない. てれまでの主要な設計法 を包含しえないこれらの設計法は，一般性に関しても そしいものになっている。

逆不安定なプラントに対する適応制御法に関して は，適応極配置法を始め，乙れまで有力な設計法がい くつか提案されている(6) 8). しかし，乙れらは基本的 にはプラントが時不変系として記述されることを前提 としたあのであり, 逆不安定なプラントが時変系とし て記述されねばならない場合の設計法は，残念ながら いまだ報告されていない.

本論文では，乙れらを踏まえ，プラントを時変系と して定式化したうえで，1 サンプリング周期以上のむ だ時間をあつ逆不安定なプラントが取り扱え，しか あ, パラメータ変動の暧昧さに頑健な設計法の導出を 
図る、ここで提案する設計法は，乙れまでの主要な設 計法を無理なく包含するという一般性の高い設計法で ある・

\section{2. 問題の記述}

適応制御の対象となるプラントとして, つぎの時変 系を考える。

$$
A\left(k, z^{-1}\right) y(k)=B\left(k, z^{-1}\right) z^{-d} u(k)
$$

乙こに, $A\left(k, z^{-1}\right), B\left(k, z^{-1}\right)$ は時変パラメ一タをあ つ，つぎのような多項式である.

$$
\left.\begin{array}{l}
A\left(k, z^{-1}\right)=1+a_{1}(k) z^{-1}+\cdots+a_{n_{A}}(k) z^{-n_{A}} \\
B\left(k, z^{-1}\right)=b_{0}(k)+b_{1}(k) z^{-1}+\cdots+b_{n_{B}}(k) z^{-n_{B}}
\end{array}\right\}
$$

なお， $z^{-1}$ は時間遅れ演算子である. 上のプラントに 対しつぎの前提を設ける.

(i) むだ時間 $d \geq 1$, 次数 $n_{A}, n_{B}$ は既知.

(ii) 時変パラメータ $a_{i}(k), b_{i}(k)$ は末知. また, $b_{0}(k) \neq 0 ; \forall k$

ここで考える制御問題は，つぎの評価関数 $J(k+d)$ を最小とするような制御入力 $u(k)$ を適応的に合成す るとととする ${ }^{7), 8)}$.

$$
\begin{aligned}
J(k+d)= & \left(C\left(z^{-1}\right) y(k+d)-D\left(z^{-1}\right) y_{r}(k+d)\right)^{2} \\
& +\left(E\left(z^{-1}\right) u(k)-F\left(z^{-1}\right) u_{r}(k)\right)^{2}
\end{aligned}
$$

ただし，

$$
\left.\begin{array}{l}
C\left(z^{-1}\right)=1+c_{1} z^{-1}+\cdots+c_{n_{C}} z^{-n_{C}} \\
D\left(z^{-1}\right)=d_{0}+d_{1} z^{-1}+\cdots+d_{n_{D}} z^{-n_{D}} \\
E\left(z^{-1}\right)=e_{0}+e_{1} z^{-1}+\cdots+e_{n_{E}} z^{-n_{E}} \\
F\left(z^{-1}\right)=f_{0}+f_{1} z^{-1}+\cdots+f_{n_{F}} z^{-n_{F}}
\end{array}\right\}
$$

\section{3. 基礎設計}

多項式 $C\left(z^{-1}\right), A\left(k, z^{-1}\right)$ に関しては，つぎのよう な多項式方程式を考えることができる.

$$
C\left(z^{-1}\right)=R\left(k, z^{-1}\right) A\left(k, z^{-1}\right)+S\left(k, z^{-1}\right) z^{-d}
$$

乙こに, $R\left(k, z^{-1}\right), S\left(k, z^{-1}\right)$ はつぎのような時変係数 をあつ多項式であり,

$$
\left.\begin{array}{r}
R\left(k, z^{-1}\right)=1+r_{1}(k) z^{-1}+\cdots+r_{n_{R}}(k) z^{-n_{R}} ; \\
n_{R}=d-1 \\
S\left(k, z^{-1}\right)=s_{0}(k)+s_{1}(k) z^{-1}+\cdots+s n_{S}(k) z^{-n_{S}} ; \\
n_{S}=\max \left(n_{C}-d, n_{A}-1\right)
\end{array}\right\}
$$

これらは，(5)式の解として一意に存在する.

(5)式の両辺に右側から $y(k)$ を乗じ，（1)式を用 いると次式が得られる.

$$
C\left(z^{-1}\right) y(k)=R^{\prime}\left(k, z^{-1}\right) u(k-d)+S\left(k, z^{-1}\right) y(k-d)
$$

ただし，

$$
\begin{aligned}
R^{\prime}\left(k, z^{-1}\right)= & R\left(k, z^{-1}\right) B\left(k, z^{-1}\right) \\
= & r_{0}^{\prime}(k)+r_{1}^{\prime}(k) z^{-1}+\cdots+r_{n_{R}^{\prime}}^{\prime}(k) z^{-n_{R}^{\prime}} ; \\
& n_{R}^{\prime}=n_{B}+d-1
\end{aligned}
$$

(7) 式は, プラントの入力 $u(k)$ と出力 $y(k)$ の関係 を示すむのであり，（1)式のプラントの別表現と考え ることができる。

(3) 式の評価関数 $J(k+d)$ は，(7)式を用いると つぎのように書き改められる.

$$
\begin{aligned}
J(k+d)= & \left(R^{\prime}\left(k+d, z^{-1}\right) u(k)+S\left(k+d, z^{-1}\right) y(k)\right. \\
& \left.-D\left(z^{-1}\right) y_{r}(k+d)\right)^{2}+\left(E\left(z^{-1}\right) u(k)\right. \\
& \left.-F\left(z^{-1}\right) u_{r}(k)\right)^{2}
\end{aligned}
$$

上式を $u(k)$ で微分すると

$$
\begin{aligned}
\frac{\partial J(k+d)}{\partial u(k)}= & 2\left(R^{\prime}\left(k+d, z^{-1}\right) u(k)+S\left(k+d, z^{-1}\right) y(k)\right. \\
& \left.-D\left(z^{-1}\right) y_{r}(k+d)\right) r_{0}^{\prime}(k+d) \\
& +2\left(E\left(z^{-1}\right) u(k)-F\left(z^{-1}\right) u_{r}(k)\right) e_{0}(10)
\end{aligned}
$$

したがって，J(k+d) を最小とする制御則はつぎのよ うに求められる.

$$
\begin{aligned}
&\left(R^{\prime}\left(k+d, z^{-1}\right)+\frac{e_{0}}{r_{0}^{\prime}(k+d)} E\left(z^{-1}\right)\right) u(k) \\
&=-S\left(k+d, z^{-1}\right) y(k)+D\left(z^{-1}\right) y_{r}(k+d) \\
&+\frac{e_{0}}{r_{0}^{\prime}(k+d)} F\left(z^{-1}\right) u_{r}(k)
\end{aligned}
$$

(11)式の制御則にしたがって制御入力 $u(k)$ を合成 するためには， $k$ 時点には $(k+d)$ 時点のパラメータ $r_{i}^{\prime}(k+d), s_{i}(k+d)$ が明らかにされていなければなら ない。しかし，てれらを定めるプラントの特性は未知 である. このためここでは，プラントの入出力信号を 利用して $r_{i}^{\prime}(k+d), s_{i}(k+d)$ を予測し, その予測值 $\hat{r}_{i}^{\prime}(k+d), \hat{s}_{i}(k+d)$ を用いて制御入力 $u(k)$ をつぎの ように合成するととにする。

\section{[制御則]}

$$
\begin{aligned}
\left(\hat{R}^{\prime}\left(k+d, z^{-1}\right)+\frac{e_{0}}{\hat{r}_{0}^{\prime}(k+d)} E\left(z^{-1}\right)\right) u(k) \\
=-\hat{S}\left(k+d, z^{-1}\right) y(k)+D\left(z^{-1}\right) y_{r}(k+d) \\
\quad+\frac{e_{0}}{\hat{r}_{0}^{\prime}(k+d)} F\left(z^{-1}\right) u_{r}(k)
\end{aligned}
$$

ただし

$$
\left.\begin{array}{l}
\hat{R}^{\prime}\left(k, z^{-1}\right)=\hat{r}_{0}^{\prime}(k)+\hat{r}_{1}^{\prime}(k) z^{-1}+\cdots+\hat{r}_{n R}^{\prime}(k) z^{-n_{R}^{\prime}} \\
\hat{S}\left(k, z^{-1}\right)=\hat{s}_{0}(k)+\hat{s}_{1}(k) z^{-1}+\cdots+\hat{s}_{n S}(k) z^{-n s}
\end{array}\right\}
$$

つぎに，(12)式の制御則におけるパラメータ $\hat{r}_{i}^{\prime}(k+$ $d), \hat{s}_{i}(k+d)$ の予測方法について考える.

\section{(注意 1 )}

本設計法では, $u(k)$ の合成に要する演算時間は, 等 価的にプラントのむだ時間に含ませて考えている. 


\section{4. パラメータ調整系の設計}

パラメータ $r_{i}^{\prime}(k), s_{i}(k)$ が不規則不確定に変化する 場合には，乙れらを $(k-d)$ 時点以前に適切に予测す るととは物理的に不可能である.このため,ここで は, 次式のように, これらがある有界な関数 $f_{i, j}(k)$, $g_{i, j}(k)$ の線形和として記述される場合について考え る.

$$
\left.\begin{array}{rl}
r_{i}^{\prime}(k) & =\sum_{j=0}^{m_{r i}} r_{i, j}^{\prime} f_{i, j}(k) \\
s_{i}(k) & =\sum_{j=0}^{m_{s i}} s_{i, j} g_{i, j}(k)
\end{array}\right\}
$$

上式は，パラメータ $r_{i}^{\prime}(k), s_{i}(k)$ が関数 $f_{i, j}(k)$, $g_{i, j}(k)$ に従って変化するととを意味するあのである. したがって, 関数 $f_{i, j}(k), g_{i, j}(k)$ およびパラメータ $r_{i, j}^{\prime}, s_{i, j}$ を知ることができれば， $d$ ステップ以前に $r_{i}^{\prime}(k), s_{i}(k)$ を正しく予測することができる. しかし， このような関数を全区間 $k \in[0, \infty)$ にわたってあらか じめ求めることは，一般には，相当の困難が予想され る.このため, ここでは, さらに, 時変パラメータが ある限定された区間 $k \in\left[k_{l}, k_{l+1}\right)$ では線形的に変化 するあのとし, $f_{i, j}(k), g_{i, j}(k)$ としては, 0 次と 1 次 の関数を考える. この関数としては, 各種の形式のあ のが考えられるが，乙こではつぎのあのを用いる.

$$
\left.\begin{array}{rl}
f_{i, 0}(k) & =g_{i, 0}(k)=1 \\
f_{i, 1}(k) & =g_{i, 1}(k) \\
& =\alpha \cdot\left(k-k_{l}+k_{\beta}\right) ; k \in\left[k_{l}, k_{l+1}\right)
\end{array}\right\}
$$

この場合には, パラメータ $r_{i}^{\prime}(k), s_{i}(k)$ はつぎのよう に表現されることになる。

$$
\left.\begin{array}{rl}
r_{i}^{\prime}(k) & =r_{i, 0}^{\prime} f_{i, 0}(k)+r_{i, 1}^{\prime} f_{i, 1}(k) \\
& =r_{i, 0}^{\prime}+r_{i, 1}^{\prime} \cdot \alpha \cdot\left(k-k_{l}+k_{\beta}\right) ; k \in\left[k_{l}, k_{l+1}\right) \\
s_{i}(k) & =s_{i, 0} g_{i, 0}(k)+s_{i, 1} g_{i, 1}(k) \\
& =s_{i, 0}+s_{i, 1} \cdot \alpha \cdot\left(k-k_{l}+k_{\beta}\right) ; k \in\left[k_{l}, k_{l+1}\right)
\end{array}\right\}
$$

上式における $\alpha, k_{\beta}$ は設計者が定める設計パラメー タであり, $r_{i}^{\prime}(k), s_{i}(k)$ を決定する $r_{i, j}^{\prime}, s_{i, j}$ は仮定 により未知である $\left(\alpha, k_{\beta}\right.$ の選定指針については 5 章 の (注意 2 ) を参照). つぎに, プラントの入出力信 号を利用した, $r_{i, j}^{\prime}, s_{i, j}$ の推定方法について考える.

（7)式は，(16)式の表現を用いると，つぎのように 書き改められる.

$$
y^{\prime}(k)=C\left(z^{-1}\right) y(k)=\theta^{T} \zeta(k) ; k \in\left[k_{l}, k_{l+1}\right)
$$
ただし，

$$
\begin{aligned}
& \theta=\left[\theta_{0}^{T}, \theta_{1}^{T}\right]^{T} \\
& \theta_{0}=\left[r_{0,0}^{\prime}, \cdots, r_{n_{R}^{\prime}, 0}^{\prime}, s_{0,0}, \cdots, s_{n s, 0}\right]^{T} \\
& \theta_{1}=\left[r_{0,1}^{\prime}, \cdots, r_{n_{R}^{\prime}, 1}^{\prime}, s_{0,1}, \cdots, s_{n, 1}\right]^{T}
\end{aligned}
$$

$$
\begin{aligned}
\zeta(k)= & {\left[\zeta_{0}^{T}(k), \zeta_{1}^{T}(k)\right]^{T} } \\
\zeta_{0}(k)= & {\left[u(k-d), \cdots, u\left(k-d-n_{R}^{\prime}\right),\right.} \\
& \left.y(k-d), \cdots, y\left(k-d-n_{S}\right)\right]^{T} \\
\zeta_{1}(k)= & \alpha \cdot\left(k-k_{l}+k_{\beta}\right) \cdot \zeta_{0}(k)
\end{aligned}
$$

(17)式に対する推定モデルとしてつぎのあのを考え る.

$$
\hat{y}^{\prime}(k)=\hat{\theta}^{T}(k) \zeta(k) ; k \in\left[k_{l}, k_{l+1}\right)
$$

ここに, $\hat{\theta}(k)$ は $\hat{\theta}$ の推定値たるつぎのような可調整 ベクトルである.

$$
\left.\begin{array}{l}
\hat{\theta}(k)=\left[\hat{\theta}_{0}^{T}(k), \hat{\theta}_{1}^{T}(k)\right]^{T} \\
\hat{\theta}_{0}(k)=\left[\hat{r}_{0,0}^{\prime}(k), \cdots, \hat{r}_{n_{R}, 0}^{\prime}(k), \hat{s}_{0,0}(k), \cdots, \hat{s}_{n s, 0}(k)\right]^{T} \\
\hat{\theta}_{1}(k)=\left[\hat{r}_{0,1}^{\prime}(k), \cdots, \hat{r}_{n_{R}, 1}^{\prime}(k), \hat{s}_{0,1}(k), \cdots, \hat{s}_{n_{s, 1}}(k)\right]^{T}
\end{array}\right\}
$$

推定モデルの $\hat{\theta}(k)$ は, 新たに開発されたつぎの時変 忘却係数を有するアルゴリズムにより調整するすのと する ${ }^{9}$.

\section{[パラメータ調整則 $]$}

$$
\begin{aligned}
& \hat{\theta}(k)= \hat{\theta}(k-1)-\frac{\mu(k) \boldsymbol{\Gamma}(k-1) \boldsymbol{\zeta}(k)}{1+\mu(k) \boldsymbol{\zeta}^{T}(k) \boldsymbol{\Gamma}(k-1) \boldsymbol{\zeta}(k)} \\
& \times\left(\hat{\theta}^{T}(k-1) \boldsymbol{\zeta}(k)-y^{\prime}(k)\right) \\
& \boldsymbol{\Gamma}(k)= \frac{1}{\lambda(k)}[\boldsymbol{\Gamma}(k-1) \\
&\left.-\frac{\mu(k) \boldsymbol{\Gamma}(k-1) \boldsymbol{\zeta}(k) \boldsymbol{\zeta}^{T}(k) \boldsymbol{\Gamma}(k-1)}{1+\mu(k) \boldsymbol{\zeta}^{T}(k) \boldsymbol{\Gamma}(k-1) \boldsymbol{\zeta}(k)}\right] \\
&\left.\begin{array}{rl}
\lambda(k)= & \max \\
\frac{1}{\gamma_{u}}[\operatorname{tr} \boldsymbol{\Gamma}(k-1) & -\frac{\mu(k)\|\boldsymbol{\Gamma}(k-1) \boldsymbol{\zeta}(k)\|^{2}}{1+\mu(k) \boldsymbol{\zeta}^{T}(k) \boldsymbol{\Gamma}(k-1) \boldsymbol{\zeta}(k)}
\end{array}\right) \\
&\left.\begin{array}{l}
\boldsymbol{\Gamma}(-1)>0, \quad \gamma_{u} \geq \operatorname{tr} \boldsymbol{\Gamma}(-1) \\
0<\lambda<1, \quad 0<\mu(k)<\infty
\end{array}\right)
\end{aligned}
$$

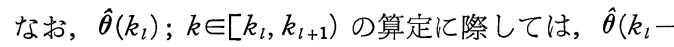
1); $k \in\left[k_{l-1}, k_{l}\right)$ より求められた次式の $\hat{\theta}^{\prime}\left(k_{l}-1\right)$; $k \in\left[k_{l}, k_{l+1}\right)$ を(21)式の右辺の $\hat{\theta}(k-1)$ に用いるす のとする.

$$
\left.\begin{array}{l}
\hat{\theta}_{0}^{\prime}\left(k_{l}-1\right)=\hat{\theta}_{0}\left(k_{l}-1\right)+\hat{\theta}_{1}\left(k_{l}-1\right) \cdot \alpha \cdot\left(k_{l}-k_{l-1}\right) \\
\hat{\theta}_{1}^{\prime}\left(k_{l}-1\right)=\hat{\theta}_{1}\left(k_{l}-1\right)
\end{array}\right\}
$$

上のアルゴリズムによれば，信号ベクトル $\zeta(k)$ の いかんにかかわらず,

$$
0<\operatorname{tr} \Gamma(k) \leq \gamma_{u}, \quad \lambda \leq \lambda(k) \leq 1
$$

が保証される ${ }^{9)}$ とのアルゴリズムは忘却係数を有し ているため, パラメータ $r_{i}^{\prime}(k), s_{i}(k)$ が(16)式で示し たような比較的長い区間 $k \in\left[k_{l}, k_{l+1}\right)$ にわたり一定 の係数 $\left(r_{i, 0}^{\prime}, r_{i, 1}^{\prime}, s_{i, 0}, s_{i, 1}\right)$ で線形表現されない場合 にあ使用できる．すなわち，本アルゴリズムは，パラ メータ $r_{i}^{\prime}(k), s_{i}(k)$ がパラメータ関数の基本区間 $k \in$ 


\section{2 昭和 61 年 11 月}

$\left[k_{l}, k_{l+1}\right)$ と独立した高いレートで変動する場合にあ 使用できる. また，ゲイン行列は忘却係数の作用によ り滑らかに更新されるのでリセットの必要はなく、リ セットゲイン方式特有の特異なパラメータ変動は生じ ない.

(21)〜 (25) 式のアルゴリズムに $k$ 時点以前の入出力 信号を用いて調整された $\hat{\theta}(k)$ を利用して， $(k+d)$ 時 点のパラメータ $r_{i}^{\prime}(k+d), s_{i}(k+d)$ はつぎのように 予測される.

$$
\left.\begin{array}{r}
\hat{r}_{i}^{\prime}(k+d)=\hat{r}_{i, 0}^{\prime}(k) f_{i, 0}(k+d)+\hat{r}_{i, 1}^{\prime}(k) f_{i, 1}(k+d) \\
=\hat{r}_{i, 0}^{\prime}(k)+\hat{r}_{i, 1}^{\prime}(k) \cdot \alpha \cdot\left(k+d-k_{l}+k_{\beta}\right) ; \\
k \in\left[k_{l}, k_{l+1}\right) \\
\hat{s}_{i}(k+d)=\hat{s}_{i, 0}(k) g_{i, 0}(k+d)+\hat{s}_{i, 1}(k) g_{i, 1}(k+d) \\
=\hat{s}_{i, 0}(k)+\hat{s}_{i, 1}(k) \cdot \alpha \cdot\left(k+d-k_{l}+k_{\beta}\right) ; \\
k \in\left[k_{l}, k_{l+1}\right)
\end{array}\right\}
$$

(12)式の制御則には，乙のようにして適応予測され たコントローラパラメータ $\hat{r}_{i}^{\prime}(k+d), \hat{s}_{i}(k+d)$ が用 いられる.

\section{5. 設計法の特色}

(i) 逆不安定プラントへの対応 ${ }^{7), 8)}$

評価関数アプローチによる本設計法は逆不安定な時 変プラントにも適用できる。しかし，乙のためには (4)式の重み多項式, 特に $C\left(z^{-1}\right), E\left(z^{-1}\right)$ を適切に 選定しなければならない。なお，(11)式より明らかの ように，E( $\left.z^{-1}\right)$ の係数が大きくなるにつれ，u(k)の 合成における $R^{\prime}\left(k+d, z^{-1}\right)$ の効果が小さくなるの で, $R^{\prime}\left(k+d, z^{-1}\right)$ の特別精度良い推定は実効的意味 を失なってくる（特性の未知なる逆不安定プラント に対して, 適切な重み多項式 $C\left(z^{-1}\right), D\left(z^{-1}\right), E\left(z^{-1}\right)$, $F\left(z^{-1}\right)$ をあらかじめ決めることはできない，てれら は，実際には，設計・試験の繰返しにより設計仕様を 満足するように選定されるととになる).

（ii）従来方式の包含

設計パラメータを

$$
D\left(z^{-1}\right)=C\left(z^{-1}\right) \text { (安定), } E\left(z^{-1}\right)=F\left(z^{-1}\right)=0
$$
および

$$
\left.\begin{array}{l}
m_{r i}=m_{s i}=0 \\
f_{i, 0}(k)=g_{i, 0}(k)=1
\end{array}\right\}
$$

と選ぶ場合には，本設計法は，従来の忘却係数を用い た代表的なモデル規範形適応制御法に帰着される。乙 のように, 本設計法は従来の代表的方法を無理なく包 含している. なお，乙れより，従来の設計法は，時変

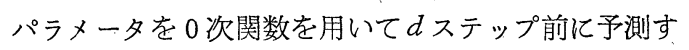
る設計法になっていたととが理解される.
第 22 巻 第 11 号

(iii) パラメータ関数の先見

全区間 $k \in[0, \infty)$ にわたって，プラントをモデリ ング誤差なく記述するためのパラメータ 関数 $f_{i, j}(k)$, $g_{i, j}(k)$ が既知なる場合には, 制御目的を正確に達成 することができる. 特にプラントが逆安定の場合に は, $D\left(z^{-1}\right)=C\left(z^{-1}\right)$ (安定),$E\left(z^{-1}\right)=F\left(z^{-1}\right)=0$ とす るととにより

$$
\lim _{k \rightarrow \infty}\left(y(k)-y_{d}(k)\right)=\lim _{k \rightarrow \infty}\left(y(k)-y_{r}(k)\right)=0
$$

を保証することができる，乙こに， $y_{d}(k)$ はプラント の時変パラメータを既知とした場合の理想的なプラン 卜出力である（この場合の安定性は，時不変プラン 卜を対象にした従来のモデル規範形適応制御法の場合 と同様な方法により簡単に証明される。（注意 3 ) 参 照).

(注意 2)

忌却係数を有するパラメータ調整則は指数減衰機能 をあつ. この機能を備えたパラメータ調整則は，実プ ラントとその数学モデルの間にモデリング誤差が存在 する場合にあ, 信号べクトル $\zeta(k)$ の P.S. 性が確保 されれば，つぎの性質を保証する ${ }^{9), 1) . ~}$

$\|\hat{\boldsymbol{\theta}}(k)\|<\infty$

また, 制御系は頑健になり, ある程度のモデリング䛊 差に対してはつぎの性質も保証される1).

$$
|e(k)|=\left|y(k)-y_{d}(k)\right|<\infty
$$

本論文のようにパラメータ関数を利用して時変パラ メータを近似予測する場合には, 信号べクトルの成分 は一般にパラメータ関数とプラントの入出力信号の積 で与えられるととになるので，パラメータ関数の形状 および個数の選択に当たっては，信号べクトルの P.S. 性を特に考慮しなければならない，乙こで特に，一つ の時変パラメータに対して，乙れをたかだか 2 個（0 次, 1 次）のパラメータ関数を利用して近似予測しよ うとしたのも P.S. 性の観点からである. また，一次 関数の導入に際し $\alpha, k_{\beta}$ なる設計パラメータを導入 したのあ同様にP.S. 性の観点からであり，乙れらは P.S. 性が高められるように選定されなければならな い. なお, 時変パラメータの変動がゆるやかな場合に は，まず 0 次近似予測を試みることが肝要である.

(注意 3)

大川氏の対象にした逆安定なプラントは，本表現法 によれば，つぎのようなパラメータ関数既知の系とし て表現される。

(i) 文献 2) のプラント

$$
\begin{aligned}
& d=1 \\
& f_{i, j}(k)=g_{i, j}(k)=\frac{1}{(k-1)^{j}}
\end{aligned}
$$


ただし

$$
C\left(z^{-1}\right)=1
$$

(ii) 文献 4) のプラント

$$
d=1
$$

$m_{r i}=m_{s i}=2$

$f_{i, 0}(k)=1, \quad f_{i, 1}(k)=\sin \left(\theta_{i} k\right), \quad f_{i, 2}(k)=\cos \left(\theta_{i} k\right)$

$g_{i, 0}(k)=1, \quad g_{i, 1}(k)=\sin \left(\omega_{i}, k\right), \quad g_{i, 2}(k)=\cos \left(\omega_{i} k\right)$ ただし，

$$
C\left(z^{-1}\right)=1
$$

本設計法によれば，大川氏のような固定ゲイン方式 の調整則に代わって, 時変ゲイン方式のものが使用で き，性能のすぐれた制御系の設計が可能になる.

\section{6. 数 值 例}

本設計法の有用性を確認するため, 数值実験を行っ た. 以下に，その 2,3 例を示す.

(i) 例 1

プラントとして，つぎの不安定システムを考える.

$\left(1+a_{1}(k) z^{-1}+a_{2}(k) z^{-2}\right) y(k)=b_{0}(k) z^{-1} u(k)$ ただし，

$$
\begin{aligned}
& a_{1}(k)=4+\sin \left(\frac{2 \pi}{180} k\right) \\
& a_{2}(k)=2+\sin \left(\frac{2 \pi}{155} k+\pi\right) \\
& b_{0}(k)=3+\sin \left(\frac{2 \pi}{135} k+\frac{3}{2} \pi\right)
\end{aligned}
$$

上のプラントに関しては，2 章で述べた前提は成立し

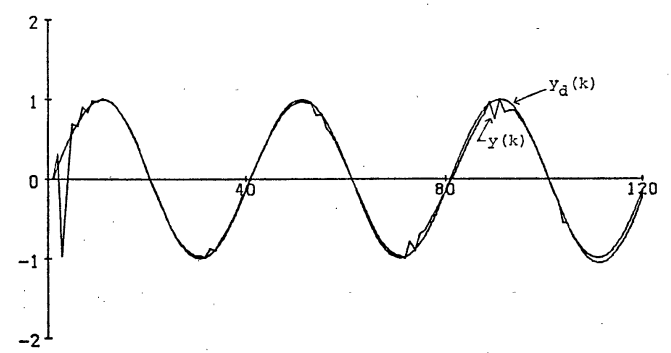

(a) Desired output $y_{d}(k)$ and controlled output $y(k)$

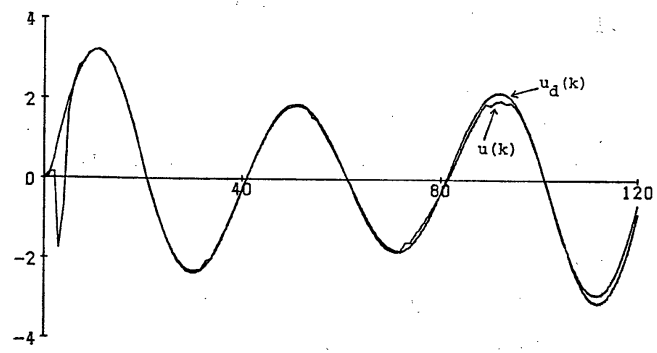

(b) Desired input $u_{d}(k)$ and synthesized input $u(k)$

\section{ているあのとする.}

設計の基本となる評価関数 $J(k+d)$ としては，つ ぎのあのを考える.

$$
J(k+d)=\left(y(k+1)-y_{r}(k+1)\right)^{2}
$$

この場合には, (12) 式の制御則における多項式 $D\left(z^{-1}\right)$, $E\left(z^{-1}\right), F\left(z^{-1}\right)$ は

$$
D\left(z^{-1}\right)=1, \quad E\left(z^{-1}\right)=F\left(z^{-1}\right)=0
$$

となる. また, $\hat{R}^{\prime}\left(k, z^{-1}\right), \hat{S}\left(k, z^{-1}\right)$ の次数は

$$
n_{R}^{\prime}=0, n_{S}=1
$$

となる. $\hat{R}^{\prime}\left(k, z^{-1}\right), \hat{S}\left(k, z^{-1}\right)$ のパラメータ $\hat{r}_{i}^{\prime}(k)$, $\hat{s}_{i}(k)$ を調整するためのパラメー夕関数 $f_{i, j}(k), g_{i, j}(k)$ としては, $m_{r i}=m_{s i}=1$ なる(15)式の形式のあのを考 え，てれらのパラメータはつぎのあのを用いる（(25) 式直後の記述および（注意 2 ）参照).

$$
f_{i, 0}(k)=g_{i, 0}(k)=1
$$

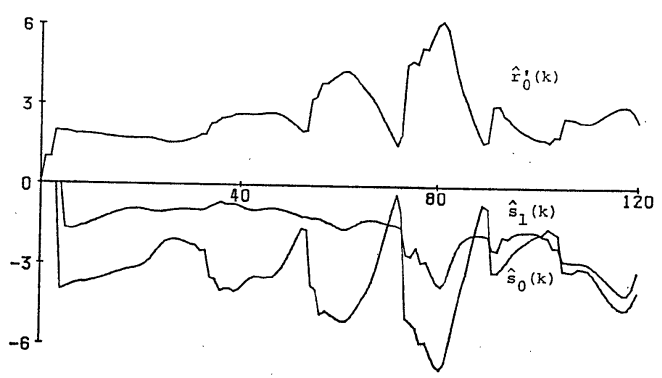

(c) Adaptively predicted controller parameters

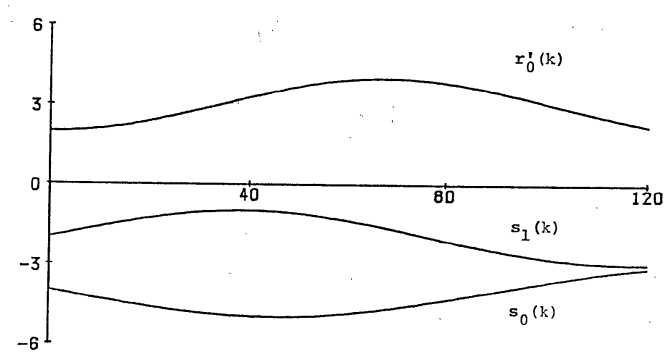

(d) Real controller parameters

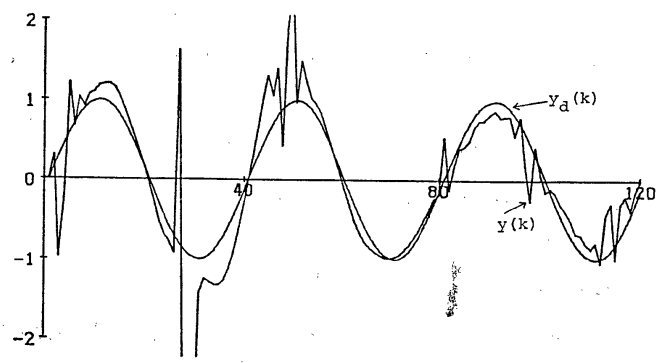

(e) Desired output $y_{d}(k)$ and controlled output $y(k)$ when zero order prediction is employed

Fig. 1 Experimental result of example one 


$$
f_{i, 1}(k)=g_{i, 1}(k)=0.1 \cdot\left(k-k_{l}-50\right) ; k \in\left[k_{l}, k_{l+1}\right)
$$
ただし，

$$
k_{l}=l \cdot 101 ; l=0,1, \cdots
$$

また，パラメータ調整則の初期值などはつぎのものを 使用する.

$$
\begin{aligned}
& \hat{\theta}(-1)=[1,0,0,0,0,0]^{T}, \boldsymbol{\Gamma}(-1)=1000 \boldsymbol{I} \\
& \gamma_{u}=\operatorname{tr} \boldsymbol{\Gamma}(-1)=6000, \lambda=0.8
\end{aligned}
$$

Fig. 1 は，上の設計に対し， $y_{r}(k)$ として周期 40 の正弦波を用いた場合の実験結果である. 同図 $(\mathrm{a})$ は 実際のプラント出力 $y(k)$ と理想的な出力 $y_{d}(k)(=$ $\left.y_{r}(k)\right)$ を, (b)は実際の制御入力 $u(k)$ と理想的な制 御入力 $u_{d}(k)$ をそれぞれ示している.また，（c）は， 適応的に予測されたコントローラパラメータ $\hat{r}_{i}^{\prime}(k)$, $\hat{s}_{i}(k)$ を, (d)は真のコントローラパラメータ $r_{i}^{\prime}(k)$, $s_{i}(k)$ である。参考までに, (e )に,

$$
m_{r i}=m_{s i}=0, \quad f_{i, 0}(k)=g_{i, 0}(k)=1
$$

とした 0 次のパラメータ予測を用いた場合のプラント 出力 $y(k)$ を示した. (a), (e)より, 乙の場合には, 1 次のパラメータ予測は 0 次のあのよりあかなりすぐ れた制御性能を発揮せしめているととがわかる.

(ii) 例 2

プラントとして，つぎの逆不安定システムを考え る.

$$
\left(1+a_{1}(k) z^{-1}\right) y(k)=\left(b_{0}(k)+b_{1}(k) z^{-1}\right) z^{-1} u(k)
$$
ただし，

$$
\begin{aligned}
& a_{1}(k)=-0.6+0.1 \sin \left(\frac{2 \pi}{150} k\right) \\
& b_{0}(k)=1+0.5 \sin \left(\frac{2 \pi}{150} k+\frac{2}{3} \pi\right) \\
& b_{1}(k)=2+0.5 \sin \left(\frac{2 \pi}{150} k+\frac{4}{3} \pi\right)
\end{aligned}
$$

上のプラントに関しては，2 章で述べた前提は成立し ているあのとする.

設計の基本となる評価関数 $J(k+d)$ としては，つ ぎのあのを考える.

$$
J(k+d)=\left(y(k+1)-y_{r}(k+1)\right)^{2}+u^{2}(k)
$$

この場合には, (12) 式の制御則における多項式 $D\left(z^{-1}\right)$, $E\left(z^{-1}\right), F\left(z^{-1}\right)$ は

$$
D\left(z^{-1}\right)=E\left(z^{-1}\right)=1, \quad F\left(z^{-1}\right)=0
$$

となる. また, $\hat{R}^{\prime}\left(k, z^{-1}\right), \hat{S}\left(k, z^{-1}\right)$ の次数は

$$
n_{R}^{\prime}=1, n_{S}=0
$$

となる. $\hat{R}^{\prime}\left(k, z^{-1}\right), \hat{S}\left(k, z^{-1}\right)$ のパラメータ $\hat{r}_{i}^{\prime}(k)$, $\hat{s}_{i}(k)$ を調整するためのパラメータ関数 $f_{i, j}(k), g_{i, j}(k)$ としては, $m_{r i}=m_{s i}=0$ とし,つぎのあのを考える.

$$
f_{i, 0}(k)=g_{i, 0}(k)=1
$$

また，パラメータ調整則の初期值などはつぎのものを

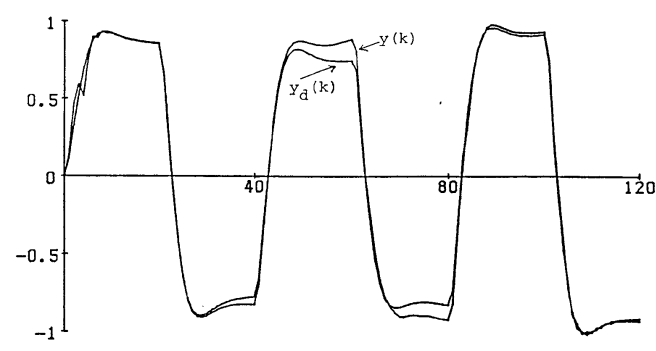

(a) Desired output $y_{\boldsymbol{d}}(k)$ and controlled output $y(k)$

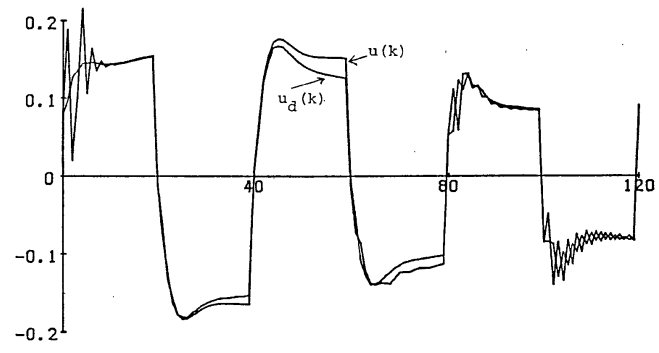

(b) Desired input $u_{d}(k)$ and synthesized input $u(k)$

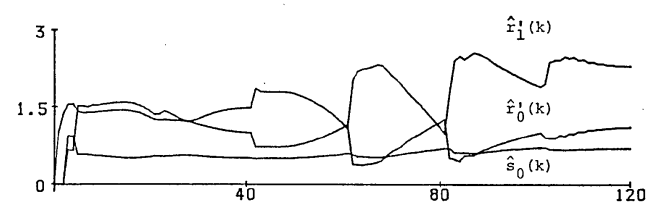

(c) Adaptively predicted controller parameters

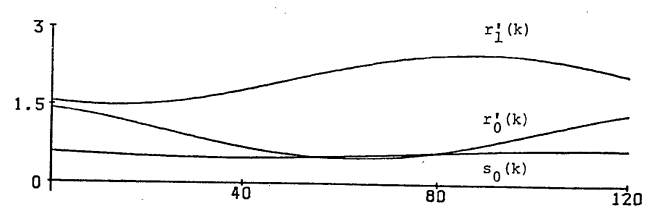

(d) Real controller parameters

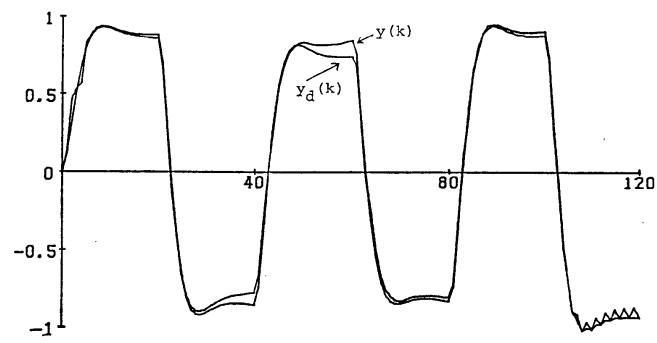

(e ) Desired output $y_{d}(k)$ and controlled input $y(k)$ when first order prediction is employed

Fig. 2 Experimental result of example two

用いる.

$\hat{\theta}(-1)=[1,0,0]^{T}, \Gamma(-1)=1000 I$

$\gamma_{u}=\operatorname{tr} \Gamma(-1)=3000, \lambda=0.85$

外部入力 $y_{r}(k)$ としては, つぎの関係で, 周期 40 , 
振幅 \pm 1 の矩形波 $y_{r}^{\prime}(k)$ より合成された信号を用い る。

$\left(1-1.33 z^{-1}+0.5 z^{-2}\right) y_{r}(k)=0.17 y_{r}^{\prime}(k)$

Fig. 2 は，乙の場合の実験結果である. 同図 (a) は実際のプラント出力 $y(k)$ と理想的な出力 $y_{d}(k)$ を, （b) は実際の制御入力 $u(k)$ と理想的な制御入力 $u_{d}(k)$ をそれぞれ示している．また，（c）は適応的に予測さ れたコントローラパラメータ $\hat{r}_{i}^{\prime}(k), \hat{s}_{i}(k)$ を, $(\mathrm{d})$ は真のコントローラパラメータである，参考までに， (e) $\mathrm{C}$

$$
\begin{aligned}
& m_{r i}=m_{s i}=1 \\
& f_{i, 0}(k)=g_{i, 0}(k)=1 \\
& f_{i, 1}(k)=g_{i, 1}(k)=0.1\left(k-k_{l}-50\right) ; k \in\left[k_{l}, k_{l+1}\right) \\
& k_{l}=l \cdot 101 ; l=0,1, \cdots
\end{aligned}
$$

とした 1 次のパラメータ予測を用いた場合のプラント 出力y $(k)$ を示した（a)，(e)より，乙の場合には， 0 次のパラメータ予測は，1 次のあのに遜色ない制御 性能を発揮せしめていることがわかる，乙の主な原因 の一つは, 評価関数の重み多項式 $E\left(z^{-1}\right)$ を比較的大 きく選定しているととによるものと思われる（5 章の (i )参照).

上掲のように，制御系は所期の性能を発揮してお り，本設計法の有用性が理解される.

\section{(注意 4)}

複数個の時変パラメータを有するプラントを制御す るためのコントローラパラメータを, プラントの入出 力信号より適応予測しようとする場合，上の 2 例が示 すように，予测パラメータは，プラントパラメータか ら直接計算された真のコントローラパラメータに必ず しも一致しない. しかし，(16)式に示されたような仮 定が成立する範囲では, 実質的制御目的は達成される ことが実験的に確認されている.

\section{7. あとがき}

以上, 時変プラントに対する適応制御法として, プ ラントを時変系として定式化したうえで，1 サンプリ ング周期以上のむだ時間をあつ逆不安定なプラントを あ扱える新しい設計法を示した。提案の設計法は, 最
近の時変プラントを対象にした設計法では扱えなかっ たプラントが扱えるばかりではなく, 従来の時不変プ ラントを対象にした主要な設計法を無理なく包含する という一般性の高い設計法になっている，本設計法の 有用性は数值実験でも示したが, 有用性の評価されて きた従来の設計法の包含性からあ理解できるものであ る.また，乙れは，乙れまでの種々の設計法の統一的 理解を可能にするあのとしてあ価值あるすのと思われ る.

プラントとその数学モデルの間にモデリング誤差が 存在する場合には，パラメータ調整に使用される信号 ベクトルの P.S. 性が重要となるが，時変プラントに おける外部入力の P.E. 性と信号ベクトルの P.S. 性 の詳しい関係の究明は残念ながらつぎの課題としてて残 された。また，ここでは，プラントに混入する外乱は 無視できるものとしたが，乙れが無視できない場合の 設計法の確立あ興味ある課題である.

\section{参 考 文 献}

1) B. D. O. Anderson and R. M. Iohnstone: Adaptive Systems and Time-Varying Plants, International J. Control, 37-2, 367/377 (1983)

2) 大川不二夫：ある種の線形時変系に対するモデル規範形 適応制御系の一設計, 計測自動制御学会論文集, 20-9, 801/806 (1984)

3) F. Ohkawa: A Model Reference Adaptive Control System for a Class of Discrete Linear Time-Varying Systems with Time-Delay, International J. Control, 42-5, 1227/1238 (1985)

4）大川不二夫：周期変動係数を有する線形時変系に対する MRACS の一設計, 計測自動制御学会論文集, 21-1, 90/ 92 (1985)

5) X. Xianya and R.J. Evans: Discrete-Time Adaptive Control for Deterministic Time-Varying Systems, Automatica, 20-3, 309/319 (1984)

6) 新中新二：適応極配置に関する一考察, 計測自動制御学 会論文集, 20-12, 1172/1174 (1984)

7) D. W. Clarke and P. J. Gawthrop: Self-Tuning Controller, Proc. IEE, 122-9, 929/934 (1975)

8）新中，鈴木：適応極配置系に関する一考察一評価関数を 有する制御系への対灾一, 計測自動制御学会論文集, 224, 476/478 (1986)

9) 新中, 鈴木: 適応システムのためのパラメータ調整アル ゴリズム, 計測自動制御学会論文集, 21-7, 691/697 (1985) 